\title{
New calculation method for tube cross-flow heat exchangers
}

\author{
Katarzyna Węglarz ${ }^{1 *}$, Dawid Taler ${ }^{1}$, Jan Taler ${ }^{1}$, and Mateusz Marcinkowski ${ }^{1}$ \\ ${ }^{1}$ Cracow University of Technology, Faculty of Environmental Engineering and Energy, ul. Warszawska 24, 31-155 Cracow, Poland
}

\begin{abstract}
A new method for thermal calculations of the cross-flow tube heat exchangers was proposed. The temperature of both fluids and the wall temperature are determined. The heat exchanger is divided into control volumes, in which outlet fluid temperatures are calculated by closed analytical formulas. Two examples of the application of the method for the calculation of two-pass cross-co-current and cross-countercurrent superheaters were presented. An exact analytical model was also developed for both superheaters to estimate the accuracy of the proposed method. The results of the superheater calculations using the developed method are in good agreement with the results obtained by the exact analytical models. The proposed method can be used to calculate heat exchangers with a complicated flow system in which the physical properties of fluids are temperature-dependent..
\end{abstract}

\section{Introduction}

Heat exchangers are among the most common apparatus both in industry and in building heating systems [1]. The book by Shah and Sekulić describes theoretical calculation methods and experimental investigations of compact heat exchangers taking into account fouling processes on their heating surfaces.

Cross-flow tube heat exchangers are one of the most widely used heat exchangers in various branches of industry as well as in air-conditioning systems and heat pumps [2].

The construction and flow systems of the heat exchangers are often complex and methods for thermal calculations of such heat exchangers are lacking. Relationships for calculating the logarithmic mean temperature difference between the fluids or their effectiveness are available in the literature only for typical flow systems of these heat exchangers [3]. Therefore, numerical or semi-analytical methods must be developed for the calculation of such exchangers, in particular when the specific heat of the fluids is temperature dependent and the flow arrangement of a tube heat exchanger is complex.

Numerical modelling and experimental studies of tubular cross-current heat exchangers are presented in [4]. The numerical modelling method of PFTHE is presented in [5]. The finite-difference method was used to determine the water and air temperature of a two-pass car radiator with two rows of tubes. The numerical model of the radiator developed in [5] was used in the simultaneous determination of heat transfer correlations on the air and water side of the car radiator in [6]. The air and water temperatures at the control volume nodes are determined from solving a system of non-linear algebraic equations using the Gauss-Seidel method. The number of iterations needed to obtain a solution with satisfactory accuracy is sometimes large and reaches several thousand. A characteristic feature of the numerical modelling method for tube heat exchangers developed in [5] is the arithmetic averaging of the flue gas temperature over the thickness of one row of tubes. Arithmetic averaging at larger gas temperature differences over the width of one tube row can lead to small errors in the determined fluid temperatures of the order of 1-2\% compared to the exact analytical solution. Taler proposed integer averaging of the gas temperature over the thickness of one row of tubes to improve the accuracy of numerical modelling of cross-flow tube heat exchangers [6].

Numerical study on the heat transfer and pressure drop characteristics of fin-and-tube surface with four roundconvex strips around each tube was carried out by $\mathrm{Li}$ et al. [7]. Different turbulence models give different results in CFD modelling. Therefore, some parameters in heat exchanger models based on CFD modelling must be adjusted using experimental studies of the heat exchangers.

The Particle-Resolved Direct Numerical Simulations (PR-DNS) were used for low-temperature densely packed beds [8]. The results of calculations using DNS agree well with the experimental results, but the computer calculation time is very long. It is to be expected that as the computing power of computers increases, this method will also find application for modelling flow and heat transfer in tubular cross-current exchangers.

In this paper, a new non-iterative calculation method for cross-co-current heat exchangers will be presented. The entire heat exchanger is divided into finite volumes. The temperatures of the two fluids at the outlet of the control volume are calculated using simple analytical formulas. This avoids the need to solve a system of non-linear algebraic equations to calculate the temperatures at the

* Corresponding author: katarzyna.weglarz@pk.edu.pl 
nodes of the finite volumes. The dependence of the physical properties of fluids on temperature and pressure can be easily taken into account in the proposed method. The method is suitable for the calculation of cross-current heat exchangers made of plain tubes, individually finned tubes, and PFTHE. It is also a fast and simple method for calculating high-temperature exchangers such as steam superheaters in sub and supercritical power boilers.

\section{A new method for thermal calculations of cross-flow tube heat exchangers}

A new numerical-analytical method for modeling tube cross-co-current and tube cross-counter-current heat exchangers is presented. All tubes in a heat exchanger of length $L_{x}$ are divided into finite volumes of length $\Delta x_{i}$. The length of a control volume is

$$
\Delta x_{i}=x_{i+1}-x_{i}, \mathrm{~m}
$$

The total length of all control volumes must be equal to the length of the pipe $L_{x}$.

$$
\sum_{i=1}^{n} \Delta x_{i}=L_{x}, \mathrm{~m}
$$

In the case of control volumes of equal length, the finite volume length is

$$
\Delta x=\frac{L_{x}}{n}, \mathrm{~m}
$$

The transverse pitch of the tube arrangement in the exchanger is $p_{1}$, and the longitudinal $p_{2}$. The tube heat exchanger has a discrete structure, characterized by heating or cooling of the fluid flowing transversely through the tubes while the gas flows outside perpendicularly to the tube axis. It is assumed that there is no heat flow between finite volumes in the region of the fluid flowing perpendicularly to the tube axis. To simplify the mathematical analysis of the tube heat exchanger, it is assumed that the fluid temperature changes across the entire width of the pitch $p_{2}$ in the direction perpendicular to the tube axis (Figure 1).

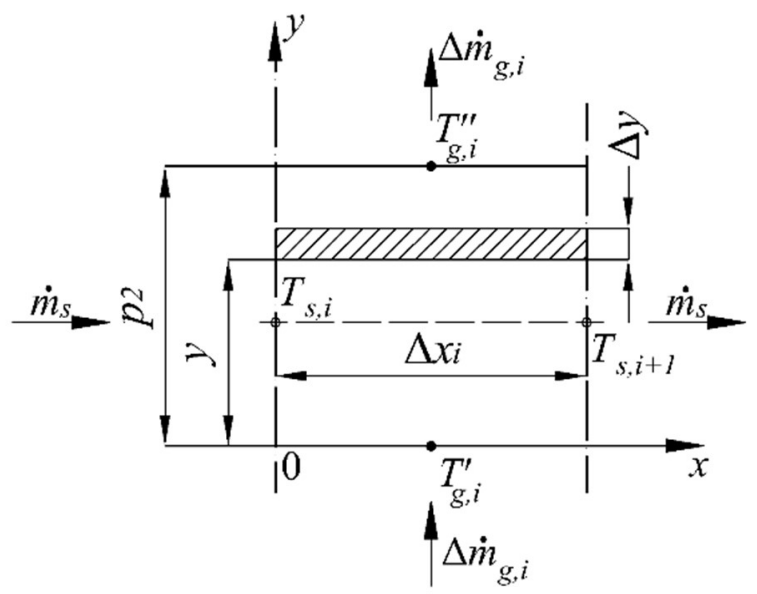

Fig. 1. Finite volume with length $\Delta x_{i}$ and width equal to $p_{2}$
The mass flow rate of the fluid flowing inside the tube is $\dot{m}_{s}$ and the mass flow rate of the fluid flowing transversely through the finite volume is $\Delta \dot{m}_{g, i}$

$$
\Delta \dot{m}_{g, i}=p_{1} \Delta x_{i} w_{i} \rho_{g, i}=p_{1} \Delta x_{i} w_{i+1} \rho_{g, i+1}, \mathrm{~kg} / \mathrm{s}
$$

In the case of equal lengths, the mass flow rate $\Delta \dot{m}_{g, i}$ of gas through the finite volumes is

$$
\Delta \dot{m}_{g, i}=\frac{\dot{m}_{g}}{n}, \mathrm{~kg} / \mathrm{s}
$$

where $\dot{m}_{g}$ is the gas mass flow rate per tube flowing through the cross section of $p_{1} L_{x}$.

The heat flow rate transferred from the hot to the cold fluid within one finite volume $x_{i} \leq x \leq x_{i+1}$ is calculated assuming that the average temperature of the fluid inside the tube is approximated by the arithmetic mean of the fluid inlet and outlet temperatures of the control volume

$$
\bar{T}_{s, i}=\frac{T_{s, i}+T_{s, i+1}}{2},{ }^{\circ} \mathrm{C}
$$

Normally, a fluid flow rate inside the tubes is high and the temperature changes along its length $\Delta x_{i}$ are small. The gas temperature varies over a width of one pitch $p_{2}$ from temperature $T_{g, i}^{\prime}$ to $T_{g, i}^{\prime \prime}$ (Figure 1). The symbol $\bar{T}_{s, i}$ in Eq. (6) denotes the average temperature of the fluid inside the tube within a control area of length $\Delta x_{i}$. The gas (flue gas) temperature is assumed to be higher than the temperature of the liquid or gas flowing inside the tubes.

The following assumptions were made to model heat transfer in the heat exchanger:

- the thermophysical properties of both fluids can be temperature-dependent,

- the temperature of the fluid in the tube changes only in the direction of its flow,

- the temperature of the fluid flowing perpendicular to the tube axis changes both in the direction of its flow and along the tubes,

- the heat transfer coefficient (HTC) and overall HTC $k_{i}$ may be different on each row of tubes and may vary along the length of the tube.

The energy conservation equation for an elementary control region of dimensions $\Delta x_{i} \times \Delta y$ has the following form

$$
\begin{aligned}
\left.\Delta \dot{m}_{g, i} c_{p g, i}||_{0}^{\left.T_{g}\right|_{y}} T_{g}\right|_{y} & =k_{i} \Delta x_{i} \Delta y\left(\left.T_{g}\right|_{y}-\bar{T}_{s, i}\right) \\
& +\left.\Delta \dot{m}_{g, i} c_{p g, i}\left|T_{g}\right|_{y+\Delta y} T_{g}\right|_{y+\Delta y}
\end{aligned}
$$

By introducing the average specific heat of gas $\bar{c}_{p g, i}$ in the temperature interval from $\left.T_{g}\right|_{y+\Delta y}$ to $\left.T_{g}\right|_{y}$, which is given by the formula

$$
\bar{c}_{p g, i}=\frac{c_{p g, i}\left|\begin{array}{l}
\left.T_{g}\right|_{y+\Delta y} \\
0
\end{array} T_{g}\right|_{y+\Delta y}-c_{p g, i}\left|\begin{array}{l}
\left.T_{g}\right|_{y} \\
0
\end{array} T_{g}\right|_{y}}{\left.T_{g}\right|_{y+\Delta y}-\left.T_{g}\right|_{y}}
$$

Eq. (7) can be written in the form

$$
\Delta \dot{m}_{g, i} \bar{c}_{p g, i}\left(\left.T_{g}\right|_{y}-\left.T_{g}\right|_{y+\Delta y}\right)+k_{i} \Delta x_{i} \Delta y\left(\bar{T}_{s, i}-\left.T_{g}\right|_{y}\right)=0
$$


Writing Eq. (9) in the form

$$
\Delta \dot{m}_{g} \bar{c}_{p g, i} \frac{\left.T_{g}\right|_{y+\Delta y}-\left.T_{g}\right|_{y}}{\Delta y}+k_{i} \Delta x_{i}\left(\left.T_{g}\right|_{y}-\bar{T}_{s, i}\right)=0
$$

and assuming that $\Delta y \rightarrow 0$ give

$$
\Delta \dot{m}_{g, i} c_{p g}\left(T_{g}\right) \frac{\partial T_{g}}{\partial y}+k_{i} \Delta x_{i}\left(T_{g}-\bar{T}_{s, i}\right)=0
$$

The differential Eq. (11) was solved by the method of separation of variables with the following boundary condition (Figure 2)

$$
\left.T_{g}\right|_{y=0}=T_{g, i}^{\prime}
$$

Assuming that the specific heat capacity of the gas inside the control volume can be approximated by the following formula

$$
\bar{c}_{p g, i}=\frac{c_{p g}\left(T_{g, i}^{\prime}\right)+c_{p g}\left(T_{g, i}^{\prime \prime}\right)}{2}
$$

To avoid iterations it can be assumed that the specific heat of the medium $g$ in a given finite volume is $\bar{c}_{p g, i}=c_{p g}\left(T_{g, i}^{\prime}\right)$ instead of calculating the average specific heat over a single tube row using the expression (13). Eq. (11) can be written in the form

$$
\frac{\partial\left(T_{g}-\bar{T}_{s, i}\right)}{\partial y}=-\frac{k_{i} \Delta x_{i}}{\Delta \dot{m}_{g, i} \bar{c}_{p g, i}}\left(T_{g}-\bar{T}_{s, i}\right)
$$

Eqs (11) and (14) are identical because the average temperature of the fluid inside the tube at the $i$-th control area is constant.

After separating the variables, Eq. (14) takes the following form

$$
\frac{\partial\left(\bar{T}_{s, i}-T_{g}\right)}{\left(\bar{T}_{s, i}-T_{g}\right)}=-\frac{k_{i} \Delta x_{i}}{\Delta \dot{m}_{g, i} \bar{c}_{p g, i}} \partial y
$$

Two-sided integration of Eq. (15) gives

$$
\begin{gathered}
\int \frac{\partial\left(\bar{T}_{s, i}-T_{g}\right)}{\bar{T}_{s, i}-T_{g}}=-\frac{k_{i} \Delta x_{i}}{\Delta \dot{m}_{g, i} \bar{c}_{p g, i}} \int \partial y+C \\
\ln \left(\bar{T}_{s, i}-T_{g}\right)=-\frac{k_{i} \Delta x_{i}}{\Delta \dot{m}_{g, i} \bar{c}_{p g, i}} y+C
\end{gathered}
$$

The solution of Eq. (17) can be written as

$$
\bar{T}_{s, i}-T_{g}=\exp C \exp \left(-\frac{k_{i} \Delta x_{i}}{\Delta \dot{m}_{g, i} \bar{c}_{p g, i}} y\right)
$$

Denoting $C_{1}=\exp C$, the expression (18) takes the form

$$
T_{g}=\bar{T}_{s, i}-C_{1} \exp \left(-\frac{k_{i} \Delta x_{i}}{\Delta \dot{m}_{g, i} \bar{c}_{p g, i}} y\right)
$$

Considering the boundary condition (12), the following is obtained

$$
C_{1}=\bar{T}_{s, i}-T_{g, i}^{\prime}
$$

After substituting (20) into (19), the expression describing the gas temperature distribution over the width of one longitudinal pitch $p_{2}$ is obtained

$$
T_{g}=\bar{T}_{s, i}-\left(\bar{T}_{s, i}-T_{g, i}^{\prime}\right) \exp \left(-\frac{k_{i} \Delta x_{i}}{\Delta \dot{m}_{g, i} \bar{c}_{p g, i}} y\right), 0 \leq y \leq p_{2}
$$

The gas temperature $T_{g, i}^{\prime \prime}$ at the outlet from the control volume is obtained by substituting $y=p_{2}$ into Eq. (21)

$$
T_{g, i}^{\prime \prime}=\bar{T}_{s, i}-\left(\bar{T}_{s, i}-T_{g, i}^{\prime}\right) \exp \left(-\frac{k_{i} \Delta x_{i} p_{2}}{\Delta \dot{m}_{g, i} \bar{c}_{p g, i}}\right), i=1, \ldots, n
$$

The heat transfer surface area $\Delta A_{i}$ for a single control volume is

$$
\Delta A_{i}=p_{2} \Delta x_{i}
$$

In a tube heat exchanger, the area of the outside surface of a tube of length $\Delta x_{i}$ is

$$
\Delta A_{\text {out }}=P_{\text {out }} \Delta x_{i}
$$

The outer circumference of the tube is $P_{\text {out }}=\pi d_{\text {out }}$, and the area of the tube in the control volume for a heat exchanger made of round tubes with an outer diameter $d_{\text {out }}$ is

$$
\Delta A_{\text {out }, i}=\pi d_{\text {out }} \Delta x_{i}
$$

After substituting the expression $p_{2} \Delta x_{i}$ in formula (22) by expression (25), we obtain

where:

$$
T_{g, i}^{\prime \prime}=\bar{T}_{s, i}-\left(\bar{T}_{s, i}-T_{g, i}^{\prime}\right) \exp \left(-\Delta N_{g, i}\right)
$$

$$
\Delta N_{g, i}=\frac{k_{i} \Delta A_{\text {out }, i}}{\Delta \dot{m}_{g, i} \cdot \bar{c}_{p g, i}}, \quad \bar{T}_{s, i}=\frac{T_{s, i}+T_{s, i+1}}{2}
$$

If the specific heat $\bar{c}_{p g}$ and the velocity of the gas in front of the tube is constant along the length of the tube, then Eq. (27) is

$$
\Delta N_{g}=\frac{k_{\text {out }} A_{\text {out }}}{\dot{m}_{g} \bar{c}_{p g}}
$$

Eq. (26) is used in the numerical model of the heat exchanger to calculate the gas temperature behind a given tube row. The gas temperature $T_{g, i}^{\prime \prime}$ at the outlet of the control volume is calculated from Eq. (26) in the iterative calculation procedure. The temperature $T_{g, i}^{\prime}$ and temperature $T_{s, i}$ are known in each control (finite) volume. The temperature of the gas $T_{g, i}^{\prime \prime}$ and the temperature of the fluid flowing in the tube $T_{s, i+1}$ at the outlet of the control volume are sought. The temperature $T_{s, i+1}$ of the fluid flowing inside the tube is not known and is calculated iteratively. First, the temperature $T_{s, i+1}$ at the outlet of the control volume is taken and the average temperature $\bar{T}_{s, i}$ and heat flow rate $\Delta \dot{Q}_{s, i}$ absorbed by the fluid flowing inside the tubes are calculated

$$
\Delta \dot{Q}_{s, i}=\dot{m}_{s} \bar{c}_{p s, i}\left(T_{s, i+1}-T_{s, i}\right)
$$

The gas temperature $T_{g, i}^{\prime \prime}$ at the outlet of the control volume, and the heat flow rate $\Delta \dot{Q}_{g, i}$ are then calculated using Eq. (26)

$$
\Delta \dot{Q}_{g, i}=k_{\text {out }, i} \Delta A_{\text {out }, i}\left(\bar{T}_{g, i}-\bar{T}_{s, i}\right)
$$

The temperature $T_{s, i+1}$ is chosen so that the following condition is achieved 


$$
\varepsilon_{Q, i} \equiv \Delta \dot{Q}_{s, i}-\Delta \dot{Q}_{g, i}=0
$$

The disadvantage of the iterative procedure for determining temperatures $T_{g, i}^{\prime \prime}$ and $T_{s, i+1}$ is the large computer computation time.

In this paper, a new method for determining temperatures $T_{g, i}^{\prime \prime}$ and $T_{s, i+1}$ which does not require iterative calculations, is presented. The linear algebraic Eq. (31) is solved for $T_{s, i+1}$ in each control volume. Substituting Eqs (29) and (30) into Eq. (31) yields

$$
\dot{m}_{s} \bar{c}_{p s, i}\left(T_{s, i+1}-T_{s, i}\right)=k_{\text {out }, i} \Delta A_{\text {out }, i}\left(\bar{T}_{g, i}-\bar{T}_{s, i}\right)
$$

where $\bar{T}_{s, i}=\left(T_{s, i}+T_{s, i+1}\right) / 2$.

The average temperature $\bar{T}_{g, i}$ of the gas over the width of one transverse pitch $p_{2}$ is given by

$$
\begin{aligned}
& \bar{T}_{g, i}=\frac{1}{p_{2}} \int_{0}^{p_{2}} T_{g, i}(y) d y \\
& =\frac{1}{p_{2}} \int_{0}^{p_{2}}\left[\bar{T}_{s, i}-\left(\bar{T}_{s, i}-T_{g, i}^{\prime}\right) \exp \left(-\frac{k_{\text {out }, i} \Delta x_{i}}{\Delta \dot{m}_{g, i} \bar{c}_{p g, i}} y\right)\right] d y
\end{aligned}
$$

After calculating the integral in formula (33), we get

$$
\begin{aligned}
\bar{T}_{g, i} & =\frac{1}{p_{2}}\left[p_{2} \bar{T}_{s, i}-\left(\bar{T}_{s, i}-T_{g, i}^{\prime}\right)\right. \\
& \left.\times\left.\left(-\frac{\Delta \dot{m}_{g, i} \bar{c}_{p g, i} p_{2}}{k_{\text {out }, i} \Delta x_{i} p_{2}}\right)\left(-\frac{k_{\text {out }, i} \Delta x_{i}}{\Delta \dot{m}_{g, i} \bar{c}_{p g, i}} y\right)\right|_{0} ^{p_{2}}\right]
\end{aligned}
$$

Transforming Eq. (34) gives

$$
\begin{aligned}
& \bar{T}_{g, i}=-\left(\bar{T}_{s, i}-T_{g, i}^{\prime}\right) \frac{1}{\Delta N_{g, i}}\left[1-\exp \left(-\Delta N_{g, i}\right)\right]= \\
& \bar{T}_{s, i}-\left(\frac{T_{s, i}+T_{s, i+1}}{2}-T_{g, i}^{\prime}\right) \frac{1}{\Delta N_{g, i}}\left[1-\exp \left(-\Delta N_{g, i}\right)\right]
\end{aligned}
$$

After substituting the expression (35) for the average flue gas temperature $\bar{T}_{g, i}$ into Eq. (32), we obtain the following linear algebraic equation for $T_{s, i+1}$

$$
\dot{m}_{s} \bar{c}_{p s, i}\left(T_{s, i+1}-T_{s, i}\right)=k_{\text {out } i} \Delta A_{\text {out } i, i}\left(T_{g, i}^{\prime}, \frac{T_{s, i}+T_{s, i+1}}{2}\right) \frac{1}{\Delta N_{g, i}}\left[1-\exp \left(-\Delta N_{g, i}\right)\right]
$$

After successive transformations of Eq. (36) we obtain

$$
T_{s, i+1}=\frac{2 \frac{\Delta N_{g, i}}{\Delta N_{s, i}} T_{s, i}+\left(2 T_{g, i}^{\prime}-T_{s, i}\right)\left[1-\exp \left(-\Delta N_{g, i}\right)\right]}{2 \frac{\Delta N_{g, i}}{\Delta N_{s, i}}+\left[1-\exp \left(-\Delta N_{g, i}\right)\right]},
$$

The number of heat transfer units $\Delta N_{s, i}$ in the finite volume $i$ is given by the formula $\Delta N_{s, i}=\left(k_{\text {out }, i} \Delta A_{\text {out }, i}\right) / \dot{m}_{s} \bar{c}_{p s, i}$ where mean specific heat can be calculated using $\bar{c}_{p s, i}=c_{p s, i}$.

In the calculation of the whole heat exchanger, the temperature $T_{s, i+1}$ is first calculated in each finite volume. The average temperature of the fluid flowing inside the tubes along the length of one control volume $\bar{T}_{s, i}=\left(T_{s, i}+T_{s, i+1}\right) / 2$ is then calculated. Knowing the temperature $\bar{T}_{s, i}$ the flue gas temperature $T_{g, i}^{\prime \prime}$ is determined using Eq. (26). In the proposed method, no iteration is used, so it is very fast. Simple analytical formulas (26) and (37) are used to calculate the temperature of the fluids at the outlets of the control volume.

\section{Numerical-analytical models of the cross-co-current and cross-counter- current superheater}

The application of the developed method will be illustrated by the example of determining the distribution of steam and flue gas temperatures in twospeed superheaters, the first of which is a cross-flow exchanger (Fig. 2a), and the second of which is a crosscurrent exchanger (Fig. 2b). The results of calculations using the numerical-analytical method presented will be compared with the results of calculations obtained using exact analytical formulae.

a)

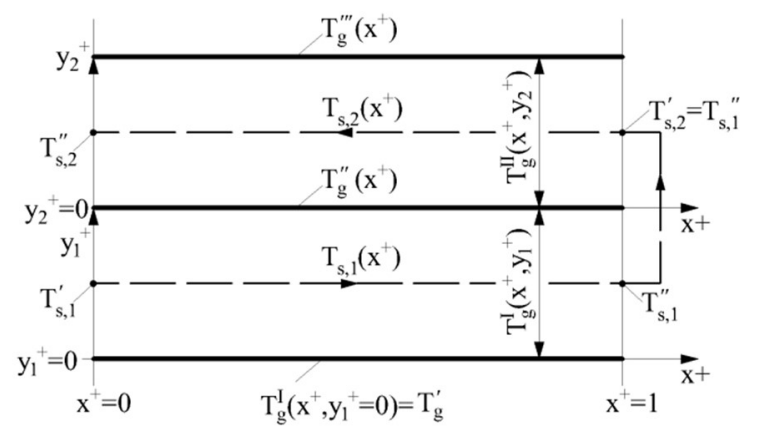

b)

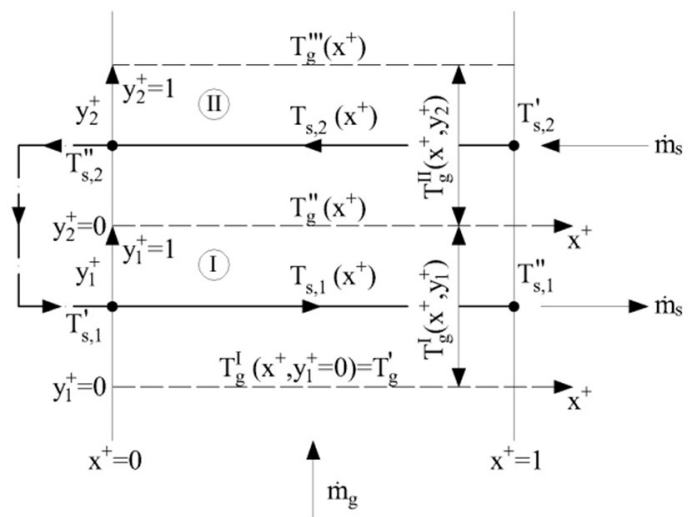

Fig. 2. Flow diagram of a two-pass cross-flow steam superheater; a) cross-co-current superheater, b) cross-countercurrent superheater.

The advantage of the cross-co-current heat exchanger is the lower maximum superheater tube wall temperature compared to the cross-counter-current heat exchanger, but its thermal efficiency is slightly lower than that of the cross-counter-current heat exchanger. 


\subsection{Two-pass cross-co-current superheater}

To evaluate the accuracy of the proposed method, the steam and flue gas temperature distributions were also determined using an exact analytical method [9].

The steam and flue gas inlet temperatures to the superheater were $T_{s, 1}^{\prime}=501.61^{\circ} \mathrm{C}$ and $T_{g}^{\prime}=977^{\circ} \mathrm{C}$. The number of heat transfer units on the steam side was $N_{g}=0.1831$ and on the flue gas was $N_{s}=0.1577$.

Table 1. Water steam temperature in the first pass of the cocurrent superheater in ${ }^{\circ} \mathrm{C}$

a)

\begin{tabular}{|c|c|c|}
\hline \multicolumn{3}{|c|}{$n=5$} \\
\hline$x_{i}^{+}=x_{i} / L_{x}$ & $\begin{array}{c}\text { Analytical } \\
\text { exact } \\
\text { method }\end{array}$ & $\begin{array}{c}\text { Present } \\
\text { method }\end{array}$ \\
\hline 0.0 & 501.61 & 501.61 \\
\hline 0.2 & 515.117 & 515.118 \\
\hline 0.4 & 528.240 & 528.242 \\
\hline 0.6 & 540.990 & 540.993 \\
\hline 0.8 & 553.378 & 553.382 \\
\hline 1.0 & 565.414 & 565.418 \\
\hline
\end{tabular}

b)

\begin{tabular}{|c|c|c|}
\hline \multicolumn{3}{|c|}{$n=7$} \\
\hline$x_{i}^{+}=x_{i} / L_{x}$ & $\begin{array}{c}\text { Analytical } \\
\text { exact } \\
\text { method }\end{array}$ & $\begin{array}{c}\text { Present } \\
\text { method }\end{array}$ \\
\hline 0.0 & 501.61 & 501.61 \\
\hline $1 / 7$ & 511.297 & 511.298 \\
\hline $2 / 7$ & 520.787 & 520.778 \\
\hline $3 / 7$ & 530.084 & 530.085 \\
\hline $4 / 7$ & 539.191 & 539.193 \\
\hline $5 / 7$ & 548.113 & 548.115 \\
\hline $6 / 7$ & 556.853 & 556.855 \\
\hline 1.0 & 565.414 & 565.417 \\
\hline
\end{tabular}

Table 2. Water steam temperature in the second pass of the co-current superheater in ${ }^{\circ} \mathrm{C}$

a)

\begin{tabular}{|c|c|c|}
\hline \multicolumn{3}{|c|}{$n=5$} \\
\hline$x_{i}^{+}=x_{i} / L_{x}$ & $\begin{array}{c}\text { Analytical } \\
\text { exact } \\
\text { method }\end{array}$ & $\begin{array}{l}\text { Present } \\
\text { method }\end{array}$ \\
\hline 0.0 & 610.697 & 610.704 \\
\hline 0.2 & 602.278 & 602.284 \\
\hline 0.4 & 593.547 & 593.553 \\
\hline 0.6 & 584.498 & 584.504 \\
\hline 0.8 & 575.123 & 575.128 \\
\hline 1.0 & 565.414 & 565.418 \\
\hline
\end{tabular}

b)

\begin{tabular}{|c|c|c|}
\hline \multicolumn{3}{|c|}{$n=7$} \\
\hline$x_{i}^{+}=x_{i} / L_{x}$ & $\begin{array}{c}\text { Analytical } \\
\text { exact } \\
\text { method }\end{array}$ & $\begin{array}{l}\text { Present } \\
\text { method }\end{array}$ \\
\hline 0.0 & 610.697 & 610.701 \\
\hline $1 / 7$ & 604.715 & 604.718 \\
\hline $2 / 7$ & 598.575 & 598.578 \\
\hline $3 / 7$ & 592.274 & 592.278 \\
\hline
\end{tabular}

\begin{tabular}{|l|l|l|}
\hline $4 / 7$ & 585.811 & 585.814 \\
\hline $5 / 7$ & 579.182 & 579.184 \\
\hline $6 / 7$ & 572.384 & 572.386 \\
\hline 1.0 & 565.414 & 565.417 \\
\hline
\end{tabular}

The comparison of the water steam temperature determined by the proposed method and the exact method [9] are presented in Tables 1a and 2a when the tube is divided into 5 finite volumes and in Tables $1 \mathrm{~b}$ and $2 b$ when it is divided into 7 finite volumes. From the analysis of the results presented in Tables 1 and 2, it can be seen that the presented method has excellent accuracy. Despite the division of the superheater tubes into a small number of finite volumes, the differences between the steam temperatures obtained by the proposed method and the exact method are negligible.

\subsection{Two-pass superheater}

cross-counter-current

The input data for the counter-current superheater calculations were the same as for the co-current superheater. An analytical model of a two-pass crossflow counter-current superheater was developed, but due to lack of space, the derived formulae are not presented here. The results of comparing the steam temperatures obtained by the developed method and the exact method are presented in Table 3 for the first pass and Table 4 for the second pass.

Table 3. Water steam temperature in the first pass of the counter-current superheater in ${ }^{\circ} \mathrm{C}$

a)

\begin{tabular}{|c|c|c|}
\hline \multicolumn{3}{|c|}{$n=5$} \\
\hline$x_{i}^{+}=x_{i} / L_{x}$ & $\begin{array}{c}\text { Analytical } \\
\text { exact } \\
\text { method }\end{array}$ & $\begin{array}{l}\text { Present } \\
\text { method }\end{array}$ \\
\hline 0.0 & 501.61 & 501.61 \\
\hline 0.2 & 513.3628 & 513.3629 \\
\hline 0.4 & 524.7303 & 524.7305 \\
\hline 0.6 & 535.722 & 535.7223 \\
\hline 0.8 & 546.3469 & 546.3474 \\
\hline 1.0 & 556.614 & 556.6145 \\
\hline
\end{tabular}

b)

\begin{tabular}{|c|c|c|}
\hline \multicolumn{3}{|c|}{$n=7$} \\
\hline$x_{i}^{+}=x_{i} / L_{x}$ & $\begin{array}{c}\text { Analytical } \\
\text { exact } \\
\text { method }\end{array}$ & $\begin{array}{c}\text { Present } \\
\text { method }\end{array}$ \\
\hline 0.0 & 501.61 & 501.6101 \\
\hline $1 / 7$ & 510.0446 & 510.0447 \\
\hline $2 / 7$ & 518.2812 & 518.2814 \\
\hline $3 / 7$ & 526.3234 & 526.3235 \\
\hline $4 / 7$ & 534.1744 & 534.1746 \\
\hline $5 / 7$ & 541.8377 & 541.838 \\
\hline $6 / 7$ & 549.3165 & 549.3168 \\
\hline 1.0 & 556.614 & 556.6143 \\
\hline
\end{tabular}


Table 4. Water steam temperature in the second pass of the counter-current superheater in ${ }^{\circ} \mathrm{C}$

a)

\begin{tabular}{|c|c|c|}
\hline \multicolumn{3}{|c|}{$n=5$} \\
\hline$x_{i}^{+}=x_{i} / L_{x}$ & $\begin{array}{c}\text { Analytical } \\
\text { exact } \\
\text { method }\end{array}$ & $\begin{array}{c}\text { Present } \\
\text { method }\end{array}$ \\
\hline 0.0 & 556.814 & 556.6145 \\
\hline 0.2 & 568.5593 & 568.5598 \\
\hline 0.4 & 580.1652 & 580.1657 \\
\hline 0.6 & 591.4413 & 591.4418 \\
\hline 0.8 & 602.3971 & 602.3975 \\
\hline 1.0 & 613.0415 & 613.0419 \\
\hline
\end{tabular}

b)

\begin{tabular}{|c|c|c|}
\hline \multicolumn{3}{|c|}{$n=7$} \\
\hline$x_{i}^{+}=x_{i} / L_{x}$ & $\begin{array}{c}\text { Analytical } \\
\text { exact } \\
\text { method }\end{array}$ & $\begin{array}{c}\text { Present } \\
\text { method }\end{array}$ \\
\hline 0.0 & 556.614 & 556.6143 \\
\hline $1 / 7$ & 565.1814 & 565.1817 \\
\hline $2 / 7$ & 573.5743 & 573.5745 \\
\hline $3 / 7$ & 581.7961 & 581.7963 \\
\hline $4 / 7$ & 589.8503 & 589.8506 \\
\hline $5 / 7$ & 597.7404 & 597.7407 \\
\hline $6 / 7$ & 605.4697 & 605.47 \\
\hline 1.0 & 613.0415 & 613.0417 \\
\hline
\end{tabular}

From the analysis of the results presented in Tables 3 and 4, it can be seen that the steam temperatures calculated using the presented method and the exact analytical method are very close to each other, as in the case of the co-current superheater. The co-current superheater is less efficient compared to the countercurrent superheater. The outlet steam temperature from the counter-current superheater is $613.04{ }^{\circ} \mathrm{C}$ and the outlet steam temperature from the co-current superheater is lower at $610.70^{\circ} \mathrm{C}$. It can be seen, however, that the differences between the outlet steam temperatures of the two superheaters are not large.

\section{Conclusions}

The developed method for non-iterative modelling of tube cross-flow heat exchangers is characterised by excellent accuracy and very short computer calculation times. Already when dividing the tube in the heat exchanger into 5-7 finite volumes, results with high accuracy are obtained. A mesh independent study should be carried out in the calculation of each heat exchanger, from which the necessary number of finite volumes along the length of the tube could be determined. The high accuracy of the method is confirmed by comparisons of the calculated steam and flue gas temperatures in the cross-co-current superheater by the proposed method with the results of calculations using the exact analytical solutions.

\section{References}

1. R.K. Shah, D.P. Sekulić, Fundamentals of Heat Exchanger Design, (2003)

2. K. Thulukkanam, Heat Exchanger Design Handbook, (2013)

3. D. Taler, Numerical Modelling and Experimental Testing of Heat Exchangers, (2019)

4. D. Taler, Theoretical and experimental analysis of heat exchangers with extended surfaces, (2002)

5. D. Taler, J Enhanc Heat Transf 11, 183-204 (2004)

6. D. Taler, Energ Convers Manage 96, 452-462 (2015)

7. X.Y. Li, Y.T. Mu, Z.H. Li, W.Q. Tao, Int J Heat Mass Tran 158, 120034 (2020)

8. Y.N. Chilamkurti, R.D. Gould, Int J Heat Mass Tran 159, $120056(2020)$

9. D. Taler, J. Taler, K. Wrona, Energy 228, 120633 (2021) 